
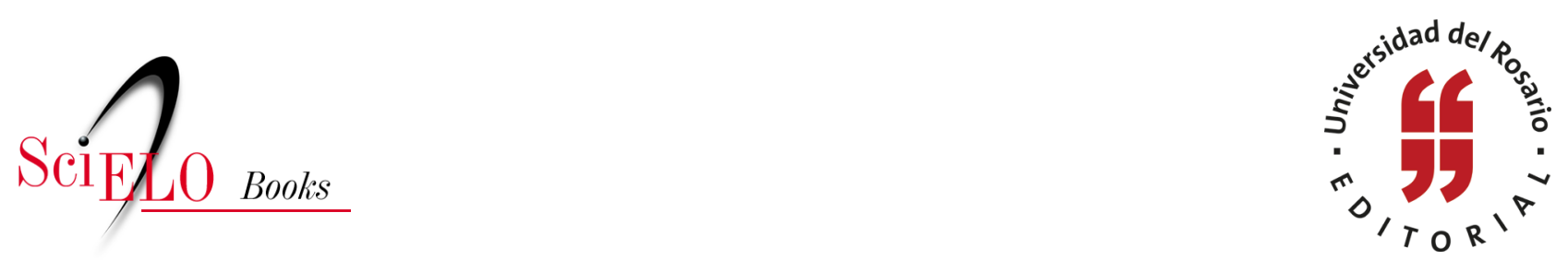

\title{
Panorama de las poblaciones excepcionales etarias frente a la responsabilidad penal
}

\author{
Carol Iván Abaunza Forero \\ Mónica Alexandra Mendoza Molina \\ Paola Bustos Benítez \\ Giovanny Paredes Álvarez \\ Karla Vanessa Enriquez Wilches \\ Andrea Carolina Padilla Muñoz
}

\section{SciELO Books / SciELO Livros / SciELO Libros}

ABAUNZA FORERO, C.I., MENDOZA MOLINA, M.A., BUSTOS BENÍTEZ, P., PAREDES ÁLVAREZ, G., ENRIQUEZ WILCHES, K.V., and PADILHA MUÑOZ, A.C. Panorama de las poblaciones excepcionales etarias frente a la responsabilidad penal. In: Adultos mayores privados de la libertad en Colombia [online]. Bogotá: Editorial Universidad del Rosario, Instituto Rosarista de Acción Social - SERES, 2014, pp. 46-54. ISBN 978-958-738-532-8.

https://doi.org/10.7476/9789587385328.0005.

All the contents of this work, except where otherwise noted, is licensed under a Creative Commons Attribution 4.0 International license.

Todo o conteúdo deste trabalho, exceto quando houver ressalva, é publicado sob a licença Creative Commons Atribição $\underline{4.0}$.

Todo el contenido de esta obra, excepto donde se indique lo contrario, está bajo licencia de la licencia Creative Commons $\underline{\text { Reconocimento } 4.0 .}$. 


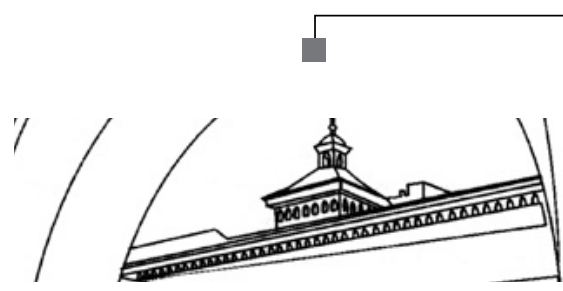




\section{Panorama de las poblaciones excepcionales etarias frente a la responsabilidad penal}


La responsabilidad es la consecuencia del delito a través de la cual se tiene al autor, cómplice o auxiliador como destinatario de la sanción prevista en la norma penal, una vez se describe el comportamiento delictivo. Nuestro estatuto represor (CP) exige que para que haya responsabilidad, el comportamiento delictivo debe ser típico, antijurídico y culpable. ${ }^{1}$

Doctrinariamente, se convalida lo anterior cuando algunos tratadistas expresan que el tema de la responsabilidad supone dos cosas: la culpabilidad del autor y, además, la necesidad de la pena desde el punto de vista preventivo, general y especial (Roxin, 2000). La pena es una reacción ante la infracción de una norma (Jakobs, 1995).

\section{Infancia y adolescencia}

No obstante que el Código de la Infancia y la Adolescencia, Ley 1098 de 2006, busca acogerse a la doctrina de la protección integral como principio rector de la Convención de los Derechos del Niño (CDN) de 1989, con el fin de instituir al adolescente como sujeto de deberes y derechos, en realidad prioriza sus derechos, así se considere la reparación del daño causado por parte de sus padres o representantes legales, tal como lo reconoce la Ley 12 de 1991 (Congreso de Colombia, 1991), que también propende por la expedición de la política pública relacionada al respecto.

Tal como lo establece la Carta Fundamental, al consagrar el derecho prevalente que le asiste al adolescente, buscando proteger no solamente su vida actual, sino también futura en sociedad, resulta esencial que la persona en sus inicios de existencia cuente con toda la atención de la familia y del Estado para alcanzar, en las mejores condiciones posibles, el estatus de persona adulta. En cuanto a su sanción, advierte expresamente que los menores de 14 años no serán juzgados, declarados penalmente responsables ni privados de la libertad por delito alguno, y en relación con las conductas delictivas de los adolescentes en que proceda la privación de la libertad, la sanción solo podrá darse en establecimientos de atención especializada en 
programas del Sistema Nacional de Bienestar Familiar, siempre y cuando estén separados de los adultos. Incluso cuando no existan establecimientos con dichas condiciones y características, se procederá a la libertad, todo ello en sintonía con la CDN, de conformidad con el artículo 49, Tratado Internacional de Naciones Unidas por el que los Estados reconocen a los niños y las niñas como sujetos de derechos.

Sin embargo, como se verá, no es equiparable ni proporcional la legislación del AM que se produce en relación con la de menores, especialmente en lo que tiene que ver con el respeto, la protección y la garantía de sus derechos. Así las cosas, el sistema de responsabilidad penal para menores contiene una serie de garantías y objetivos diferenciales que se presentan a continuación (figura 1), con base en la Ley 1068 de infancia y adolescencia, que debe tenerse como marco referente para una efectiva protección y alcance normativo para la guarda de los derechos de los AM.

La participación de los actores que se dan a conocer en la figura 2 es vital y debe ser articulada; se pretende emular esta misma coordinación para la protección de los AMPL. Las sanciones a las que pueden ser sometidos los niños, las niñas y los adolescentes declarados penalmente responsables, según el Código de la Infancia y la Adolescencia, son: la amonestación, reglas de conducta, prestación de servicios a la comunidad, libertad asistida, internación en un medio semicerrado y privación de la libertad en un centro de atención especializado. ${ }^{2}$ La privación de la libertad solo se aplica de manera excepcional, ${ }^{3}$ extremo sancionatorio que cuenta con un procedimiento especial, la intervención de una serie de funcionarios expertos y unos establecimientos, de igual manera, especializados.

La privación de la libertad solo se da hasta por 5 años para delitos graves y 8 años para delitos gravísimos como el homicidio, el secuestro y la extorsión; entre 16 y 18 años solo hay restricción de la libertad; si la infracción está castigada con más de 6 años, sumado todo ello al déficit de cupos que se presenta en los centros de reclusión, la persona adquiriría la

2 Artículo 177 de la Ley 1098 de 2006 (Código de la Infancia y la Adolescencia), modificado por el artículo 89 de la Ley 1453 de 2011.

3 Artículo 161 de la Ley 1098 de 2006 (Código de la Infancia y la Adolescencia). 
Figura 1. Sistema de responsabilidad penal para adolescentes

\author{
Es el conjunto de principios, normas, procedimientos, autoridades judiciales \\ especializadas y entes administrativos que intervienen en la investigación y el \\ juzgamiento de los delitos cometidos por personas que tengan entre 14 y 18 años. \\ Ley de infancia y adolescencia.
}

\section{Objetivo}

El Código busca establecer medidas de carácter pedagógico, privilegiando el interés superior del niño y garantizando la justicia restaurativa, la verdad y la reparación del daño.

Derechos en la privación de la libertad

- Permanecer internado en la misma localidad, municipio o distrito más próximo al domicilio de sus padres, representantes o responsables.

- Garantizar al adolescente un lugar con condiciones de higiene, seguridad y salubridad y acceso a los servicios públicos.

- Ser examinado por un médico inmediatamente después de su ingreso al programa de atención especializada.

- Continuar con su proceso educativo.
Recibir información sobre el reglamento interno de la institución donde cumplirá su sanción.

- No ser trasladado arbitrariamente del programa donde cumple la sanción.

- No ser sometido a ningún tipo de aislamiento.

- Mantener correspondencia y comunicación con sus familiares y amigos, recibir entrevistas por lo menos una vez a la semana.

- Tener acceso a la información de los medios de comunicación.
Derechos. Ser citados como testigos en los procesos penales que se adelantan contra los adultos. Su declaración solo podrá ser tomada por el defensor de familia.

La provación de la libertad es excepcional y solo podrá definirse hasta por 5 años para delitos graves y 8 años para delitos gravísimos (homisidio doloso, secuestro o extorsión).

- Derecho al debido proceso penal y sus garantías como presunción de inocencia, asesoramiento, presencia de sus padres o tutores.

- No podrá ser investigado, acusado ni juzgado por acto u omisión, en el momento de la ejecución del delito que no esté previamente definido en la ley penal vigente.

- Solo podrá ser sancionado con la imposición de las medidas definidas en el Código de la Infancia y la Adolescencia.

Fuente: elaboración propia.

libertad o la sustitución de la medida, si no hay cupo disponible para hacerla efectiva. ${ }^{4}$ Ello considerando que el menor no solamente delinque cuando es utilizado por el crimen organizado, sino que en muchas ocasiones la decisión de trasgredir la ley obedece a una decisión autónoma sin ninguna clase de presión social o familiar.

Tan exclusivo resulta el tratamiento penal de los adolescentes que se sigue pensado que es un sistema que continúa salpicado de impunidad, frente a ese cúmulo de garantías y protecciones, precisamente por el trato que la ley les da cuando se determina su autoría y responsabilidad en la co-

4 Artículo 162 de la Ley 1098 de 2006 (Código de la Infancia y la Adolescencia). 
Figura 2. Algunos actores del sistema

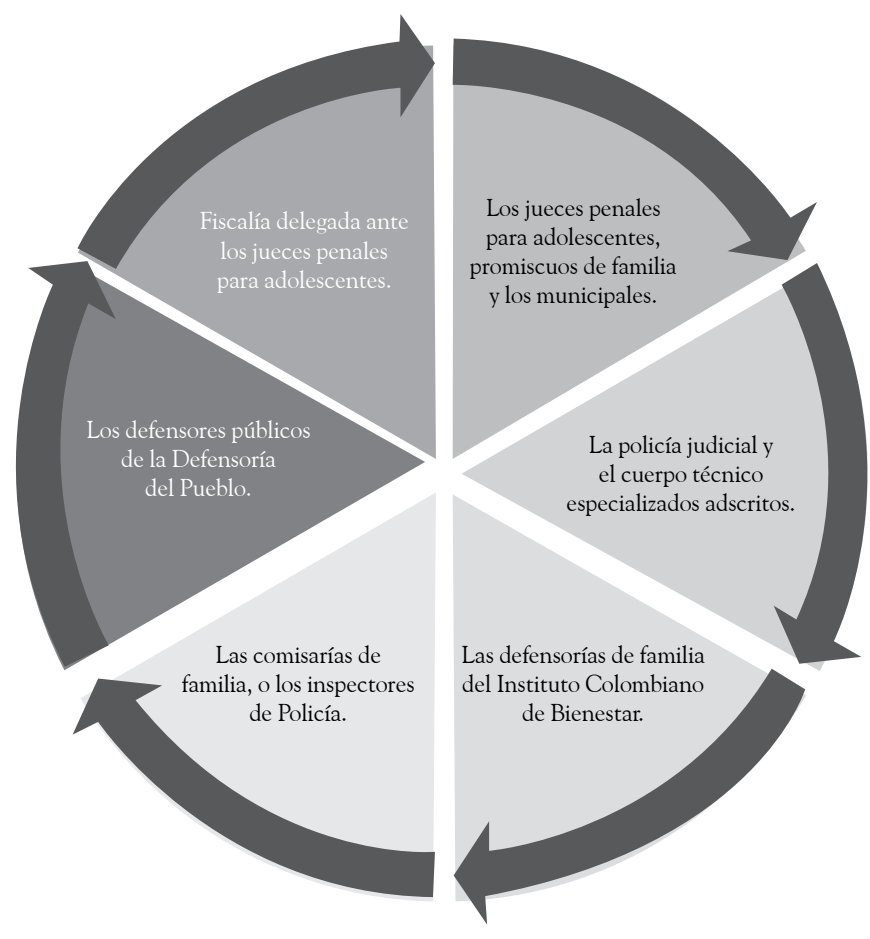

Fuente: elaboración propia.

misión de hechos delictivos, y esta es una de las causas de la reincidencia en el delincuente adolescente; de allí que no sea un tema pacífico por tratar en el ámbito de la política criminal y penitenciaria, en el que en ocasiones se reclama una respuesta más enérgica para con el delincuente menor de edad, toda vez que se superpone en este caso el derecho penal de autor al derecho penal de acto.

Ciertamente, resulta como causa eficiente de la manifestación delincuencial de menores adolescentes la propia conducta del sujeto, muchas veces desposeída de principios y valores, de la crisis del núcleo familiar de donde proviene, de las falencias que genera el modelo educativo nacional, lo que se aúna a un Estado carente de un sistema penal adecuado y desarrollado para su corrección y tratamiento (Álvarez et al., 2008). 


\section{Adulto mayor}

Si bien el menor debe contar con todas las garantías procesales, llama la atención que esa situación no se generalice o se comparta con grupos en igual o acrecentada condición de debilidad, específicamente como ocurre con el AM, quien debe contar con un sistema o pautas de responsabilidad penal especial, como ocurre con el adolescente; es decir, con unas garantías mínimas relativas a establecer las condiciones físicas, psíquicas y sociales de dicho sujeto activo, que pudieran haber tenido incidencia en la conducta imputada, toda vez que su sola condición de AM, en términos de razonabilidad, proporcionalidad y de cara a la administración de justicia, aminora en forma grave sus derechos fundamentales, como el acceso a la justicia, el debido proceso, el derecho a la defensa, entre otros, por lo que tendría que ser extraído de los parámetros generales de investigación y juzgamiento, como en efecto acontece con el adolescente, dado su estado de limitación e indefensión; estado procurado, en la mayoría de las veces, por sus circunstancias endémicas, económicas, sociales, culturales e incluso políticas, que lo hacen propenso a la discapacidad, la pobreza, la marginación, factores que maximizan su situación de dependencia, dado que no está en igualdad de condiciones que los demás (Dueñas, 2011).

Lo anterior por cuanto no existe una regulación normativa que reconozca ese estado de vulnerabilidad en relación con el derecho penal colombiano, considerando que la responsabilidad penal es el sometimiento de una persona que vulnera la norma impuesta por el derecho penal, conducta que la hace merecedora y destinataria de las consecuencias que le impone la misma ley, vale decir, la pena, según lo mencionado. Así las cosas, frente a la responsabilidad declarada por el Estado a través del aparato jurisdiccional, surge la necesidad de considerar especialmente la persona destinataria de la pena, como es obvio, para efectos de buscar su resocialización o reinserción social positiva.

El sistema penal colombiano, respecto de los AM, solo exige como presupuesto de sanción sobre responsabilidad penal —así haga alusión a conductas dolosas o culposas - los mismos parámetros que rigen para cualquier sujeto activo del delito, sin ninguna consideración especial, como sî 
sucede con los adolescentes, para quienes contempla especiales condiciones para su procesamiento y sanción.

Sin embargo, resulta obvio que ese presupuesto de responsabilidad penal en la persona mayor no es equitativo ni ponderado, y se toma como un elemento generalizado de investigación y juzgamiento, como ocurre en la actualidad. De allí que la persona mayor debe ser considerada como un sujeto activo especial de delito, no para vestirlo con un ropaje de impunidad o presumirlo inimputable - lo que llevaría a extremos, aunque en ocasiones pueda llegar a serlo-, sino con el fin de que sea concebido como un sujeto personal y socialmente merecedor de un trato especial, de un acompañamiento exclusivo, de un tratamiento diferente, que le permita como sujeto de derechos alcanzar la rehabilitación y la socialización, lo que se supone justifica la pena, así se encuentre en las postrimerías de su existencia, por cuanto sigue siendo persona y poseedor de sueños y esperanzas; al respecto, resulta consecuente invocar a Luigi Ferralloli, al tratar sobre el principio de la pena mínima necesaria y el respeto a la persona, cuando manifiesta que "un Estado que mata, que tortura, que humilla a un ciudadano no solo pierde cualquier legitimidad, sino contradice su razón de ser, poniéndose al nivel de los mismos delincuentes" (1997).

De igual manera que sucede con el adolescente infractor, resultaría necesario dar al infractor AM un trato especial dado que la respuesta institucional que se da en relación con la investigación, el juzgamiento y la sanción no contempla tratos diferenciales de mayor envergadura, como se puede corroborar a través de las distintas instituciones procesales. Los eximentes de responsabilidad que consagra el artículo 32 del CP no hacen alusión a situaciones relativas a la condición de AM, predicables por la vulnerabilidad a la que está expuesto, como se dijo anteriormente; tampoco, como lo revela el artículo 55 del CP, en relación con las circunstancias de menor punibilidad, salvo las referentes a las condiciones de inferioridad psíquicas determinadas por la edad a las que se refiere en su numeral 9 , pero no se alude específicamente a la edad.

Cuando se inicia la judicialización del AM, tampoco se establecen señalamientos específicos en relación con dicha circunstancia, a excepción de la posibilidad de sustituir la detención preventiva que se refiere en el artículo 
54

314.2 de la Ley 906 de 2004, modificado por el artículo 27 de la Ley 1142 de 2007, cuando el imputado o acusado es mayor de 65 años, siempre que su personalidad, la naturaleza y modalidad del delito hagan aconsejable su reclusión en el lugar de residencia. 